\title{
Education quality improvement due to automated virtual reality system
}

\author{
A $N$ Bogdanov*, I A Ryabykh and A I Galiev \\ KSPEU, Kazan, Krasnoselskiy str., 51, 420066, Russian Federation
}

\begin{abstract}
The paper discusses options for the implementation of virtual reality training classes with the possibility of using the developed training software and hardware complex "Substation of $110 / 35 / 10 \mathrm{kV}$ ".
\end{abstract}

\section{Introduction}

According to the Russian and international statistics, non-compliance of safety regulations is often the most common cause of emergency situations. From $60 \%$ to $90 \%$ of all injuries are associated with carelessness and mistakes of workers [1, 2]. Regular trainings of staff have been adopted as an efficient means of reducing the accident rate of production. The use of computer simulators for training operators of potentially dangerous technological processes is included in regulation documents of many countries, including Russia [3, 4].

The power engineering industry also uses various full-scale and computer simulators. With the development of information technology, virtual reality simulators (VR) began to appear and are tested. The most famous VR simulator in the power engineering industry are simulators for servicing electrical substations. More and more Russian companies servicing electrical substations are beginning to use VR simulators. This is due to the combination of advantages of full-scale and computer simulators. VR simulators are more realistic compared to classic computer simulators and are more accessible than full-scale ones. Due to this, it can be concluded that the introduction of VR simulators to the power engineering sector will be more actively in the future.

Such developments are very rarely used in education in comparison with the Russian enterprises of the power engineering industry. However virtual simulators are most relevant in high schools and professional institutions. While employees of companies can gain practical experience at real facilities, students can develop the necessary skills when servicing much more difficult energy facilities. Few people manage to effectively combine work in their specialty and study. Production practice is limited in time.

The VR simulators allow to "plunge" the student into the role of an employee in the chosen specialty, without interrupting the educational process and gain primary skills. Such simulators do not replace practice in the enterprise, but generally improve the training of students. Due to their versatility, VR simulators will allow using different scenarios, using the detailing and visualization, to show the device of the object and the physical processes occurring in it. This will help the student to quickly and easily understand the increasingly complex technical devices and more effectively engage in the learning process. A VR simulator is a good solution when there is no opportunity to acquire or operate a full-scale analogue.

Despite the increase in the number of computer classes, the potential of virtual reality and the effectiveness of such solutions, today the majority of universities and professional educational institutions do not consider the possibility of creating virtual reality training classes (VRTC). The introduction of VRTC can lead to a significant transformation of the modern educational process. Classes implemented based on automated virtual reality systems will be able to combine training and simulator components.

\section{Methods}

\subsection{Virtual reality simulator "Substation of $110 / 35 / 10$ kV"}

The virtual reality simulator "Substation of $110 / 35 / 10$ $\mathrm{kV}$ " is intended for training staff in diagnostic and repair work at energy facilities, in particular at the $110 / 35 / 10$ $\mathrm{kV}$ Nurlaty substation. Such an automated training complex can be applied in the university. The use of permanent hardware of the training complex with a wide choice of virtual objects, technological processes and scenarios will create significant opportunities for training and testing students in various specialties of the power engineering industry.

\subsection{Virtual reality simulators}

The most typical solutions in the field of virtual reality for learning include $[5,6]$ :

- Virtual lessons;

\footnotetext{
$\bar{*}$ Corresponding author: ban83@mail.ru
} 
- Virtual simulator systems.

Most of virtual lessons allow the student to "move" into a virtual laboratory and perform various experiments. Basically, these applications are designed for physics, chemistry, and are focused on schoolchildren. Examples of such developments are:

- MEL Chemistry - chemical kits with interactive tutorials in a virtual reality mobile application. It allows one to look inside the process and see what is happening at the molecular level. The virtual reality application is aimed at increasing the understanding of the essence of chemical processes;

- Labster is the interactive project that allows performing scientific experiments in a virtual laboratory. It allows the student to conduct high-cost or inaccessible at home experiments;

- Physics lesson from VRAr lab is devoted to the topic of electric current and demonstrates the work of the simplest power grid.

Most of virtual simulator systems are developed in the interests of commercial enterprises [7, 8, 9]. Examples of virtual simulator systems are:

- Virtual simulator of electrician "Russian Reailways";

- Virtual simulators for electrical substations;

- Virtual simulators for medical industry;

- $\quad$ Highly specialized virtual simulators. Examples of such developments can be simulators for learning to work on a laser cutting machine.

The main advantage of virtual complexes is its universality, i.e. with the same hardware it is possible to use various programs and scenarios for training. Thus, in the same VRTC, it is possible to conduct lectures, practical, experimental, test classes in various specialties.

\subsection{Automated virtual reality system for students teaching}

The function of an automated learning virtual reality system is "immersion" of a student in a digitized space with a pre-selected event algorithm, but with relative freedom of action.

We consider virtual reality on the example of the developed simulator "Substation of 110/35/10 kV". A student wearing a virtual reality helmet appears at a virtual test polygon, which imitates electrical substation (figure 1). During the training examiner sets appropriate tasks for him, for example, "Find and repair the damage of one of the supply lines". After that, the student needs to analyze, find the fault and eliminate it within the allotted time. The student will be in the virtual space, but due to the combination of influences on the senses, he will feel himself in the same stressful situation as in real life. Manipulators are used to interact with objects in the virtual space (figure 2). Due to their use in an automated training complex, such tasks as sequential analysis and collection of an object, etc. are presented.

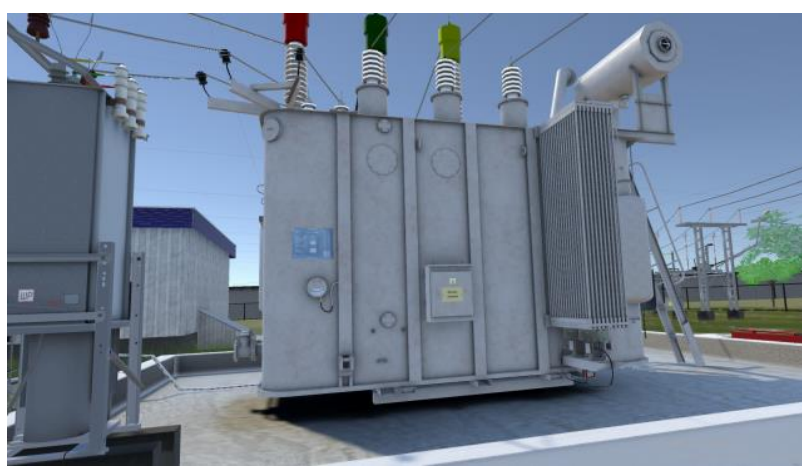

Fig. 1. Inspection of the transformer for defects.

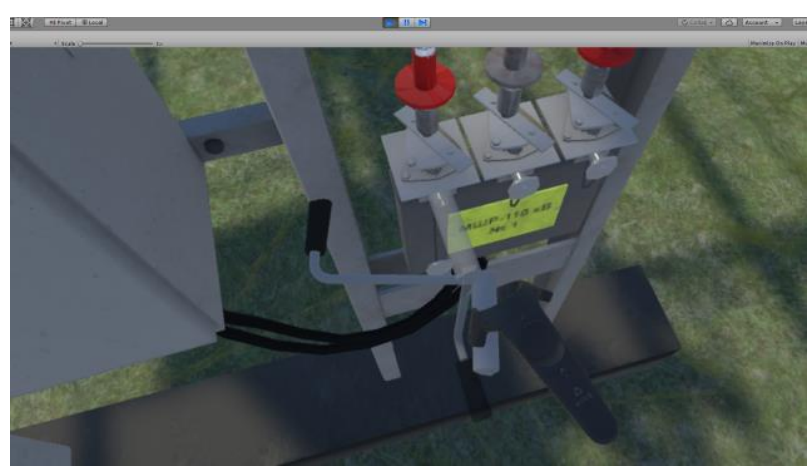

Fig. 2. Separation of knives of an open switchgear.

In case of making a mistake at one of the stages, the simulator fixes it and reflects it at the completion of the task, it also allows one to display full statistics of practical work and focus on what needs to be repeated.

Automated virtual reality system for students teaching includes:

- Hardware consisting of a computing device and virtual reality hardware (virtual reality helmet, manipulators, sensors);

- $\quad$ Specialized software.

The following features are implemented in the simulator:

- User movement in virtual space;

- Displaying the test information in the form of prompts, information about the task, the surrounding objects, and the necessary tools for working at the electrical substation;

- Playback of audio information about the task, the surrounding objects, the necessary tools for working at the electrical substation.

Moving for close distances in the virtual space occurs with the help of manipulators. The user, by clicking on the "Joystick" button of the right manipulator, sees a point in the form of a target in front of him, to change the point of movement, he holds the "Joystick" button and changes the position of the right manipulator in space. 


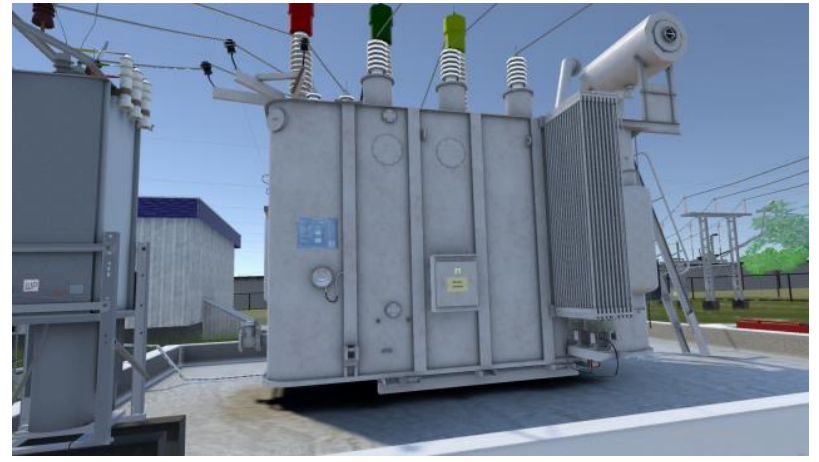

Fig. 3. Checking the operation of the algorithm for inspecting the box of a complete outdoor switchgear.

Interaction with the objects of inspection is as follows - the user visually inspects the objects, and then draws conclusions and notes the defects in the $\log$ of defects, if they are found (figure 3). In order to mark a defect in the log, the user needs to perform the following steps:

- Press the call button of the right manipulator defect log;

- Wait for the log to appear in the virtual hand;

- $\quad$ Scroll to the object's page;

- Find the defect in the list of defects and set the status "defect found".

For different types/models of objects of inspection, the list of defects differs and corresponds to the instruction "Guidelines for the production of equipment inspections (23.06.10)". If the user judges that there are no defects, then he does not make any changes to the $\log$. In order to select one or several values, the user must point the right manipulator with a laser pointer to the selected defect and press the "Trigger" button. After performing these actions, a check mark appears on the right side of the selected value. To cancel the selected defect, click on the same value again. As soon as the user finishes the selection of defects, he must click on the "Write to the log" button at the bottom of the log. This button closes the log and also performs the function of the "final answer" to the question; after pressing it, the inspection object ceases to be active for the user, i.e. he cannot change his answers. Each type of equipment of the virtual landfill electrical substation interactive actions are unique and correspond to the instructions for conducting switching in electrical installations.

\section{Results}

\subsection{Virtual reality training classes}

The virtual reality training class (VRTC) is the next stage in the evolution of conventional computer training classes. Based on the analysis of existing solutions and the ongoing developments in augmented, virtual, and mixed reality, the following possible implementation options for VRTC are possible:

- Using virtual reality glasses and mobile devices;

- Using a virtual reality helmet;

- Using mixed reality glasses/helmet;
- Using screens/projection equipment.

The solution based on virtual reality glasses and mobile devices stands out for its affordable price. The price of 1 workplace depends on the set of glasses cost plus a smartphone, on average, from 6,000 to 20,000 rubles $(\$ 100-300)$ (prices are given without regard to the software component). But this solution does not allow achieving sufficient realism and has significant limitations on the quality of graphics and the possibilities of the scenarios. It is already possible to implement such VRTCs on the basis of specialized universities due to the affordability of hardware and existing software products (for example, for electrical substations after optimizing the application for mobile devices).

The use of a virtual reality helmet greatly expands the possibilities of training scenarios and graphics. As a result, the realism of the virtual space increases. But such a decision will require large financial costs for 1 workplace, i.e. a computer plus a virtual reality kit (helmet, manipulators, sensors) - about 240,000 rubles (about \$ 3600). Adding a wall screen will increase the ability of the teacher to comment on the training, its price is from 10 to 50,000 rubles (up to $\$ 800$ ). An omnidirectional treadmill for virtual reality will require about 450,000 rubles ( $\$ 6800)$, but will further increase the realism of the student's actions. The addition of virtual reality gloves also increases realism, but they are still being developed. Such VRTC are still the most effective solution, but also costly - in the next 3-5 years they won't be implemented widespread. The situation will significantly change after the launch of 20-30 such training classes and the presentation of their effectiveness at various educational conferences.

Developments in the field of mixed reality are still underway. VRTC using a similar solution can be implemented by virtual projection of the image on real surfaces in the room, for example, on the walls. A student wearing a mixed reality helmet will see virtual objects against the background of a real wall. The result is a combination of virtual space and real space - the need for an omnidirectional treadmill disappears - the student's movement in the digital model will coincide with his physical movement in the classroom.

VRTC using screens/projection equipment - the walls of the room are lined with screens or an image is projected onto them using projectors. Such solutions are already being implemented in a number of museums. A student, having entered a similar class, sees images on the walls; can "interact" with them, but realism in this case is lower than that in the second and even in the first variant of VRTC.

\section{Discussion}

\subsection{Factors affecting the development of virtual reality in education}

Alexander Brychkin, General Director of the Russian Textbook Corporation, during the session "Investing in ED Tech" at the ED Summit educational forum in 2018 also noted good prospects for the development of virtual 
reality technology in education. International studies show that when working with $3 \mathrm{D}$ objects, up to $95 \%$ of what a person perceived or did remains in memory. At the same time, when working with two-dimensional objects and classical media, information supply is about $50 \%$.

The effectiveness of the use of virtual reality in education has been repeatedly noted by various authors, including that obtained on the basis of practical experiments. Antropova D.S. and Manshin M.E. in the article "Prospects for the use of virtual reality in primary education" reviewed the lesson conducted by St. Petersburg. It was noted that the children were able to feel the full involvement in the lesson and the subject of conversation, better understood, perceived and memorized information, and also actively participated in the discussion of this topic. In 2010 Yu.P. Zinchenko and his co-writers noted the advantages of virtual reality over traditional learning tools. They also identified the following limiting factors for the development of virtual reality in education - the high price of hardware and software. After 8 years, we have to admit that in general the situation concerning usage of virtual reality in education has not changed much [10-13].

Despite the significant number of laudatory articles on the topic of the prospects of virtual reality, including that in education, the actual use of this technology is still insignificant. This is caused by a number of negative effects and barriers, including social and medical [14, $15]$.

\section{Conclusions}

The modern world is characterized by the development of information technologies and ever-growing devices and processes. This poses new challenges to the education system, but also creates opportunities for its development. Training classes using automated virtual reality systems are no longer elements of a fantastic future, but a real and affordable tool for transforming the educational process to the increasing demands of the modern technological order.

\section{References}

1. Yu.A. Shcherbatykh, Psychology of Labor and Personnel Management, 248 (2011)

2. A.N. Lieberman, Technogenic Safety: The Human Factor, 101 (2006)

3. N.D. Zaripova, The human factor is the main cause of industrial accidents, Industrial and environmental safety, labor protection, 1(98), 21 (2015)

4. V.M. Dozortsev, D.V. Kneller, Technological computer simulators: everything you always wanted to know, Industrial control systems and controllers, 12, 1-13 (2014)

5. V.V. Selivanov, L.N. Selivanova, Virtual reality as a method and means of learning, Educational technologies and society, 17(3), 378-91 (2014)
6. S.F. Sergeev, Virtual simulators, Problems of the theory and design methodology of the Biotechnosphere, 2(8), 15-20 (2010)

7. A.I. Kuvshinova, Use of virtual reality tools for training the personnel of the enterprise, Naukarastudent.ru, 10(034), 6 (2016)

8. A.L. Gorbunov, Airfield Special Equipment Simulator, Scientific Herald of the Moscow State Technical University of Civil Aviation, 225(3), 92 97 (2016)

9. D.N. Zerfus, A.A. Ulyanovskiy, Virtual reality as a new research technology and educational environment, Bulletin of the St. Petersburg University of the State Fire Service EMERCOM of Russia: Scientific and analytical journal, 185-90 (2015)

10. D.S. Antropova, M.E. Manshin, Prospects for the use of virtual reality in primary education Student, electron. scientific journals, 17-24(44), 20-5 (2018)

11. Yu.P. Zinchenko, G.Ya. Menshikova, Yu.M. Bayakovsky, A.M. Chernorizov, A.E. Voyskunsky, Virtual reality technologies: methodological aspects, achievements and prospects, National Psychological Journal, 1(3), 54-62 (2010)

12. G.V. Knyazeva, Virtual reality and professional visualization technologies, Bulletin of the Volzhsky University. V.N. Tatishcheva, 12, 68-76 (2010)

13. S.D. Markin, M.In. Stupina, The current state of the virtual reality industry and the immediate prospects of its Innovations in science, Sat. Art. on mater. LXII int. scientific-practical conf., 34-40 (2016)

14. E.O. Kolesnikov, The Impact of Virtual Reality: Man and a Computer Game: A Philosophical Aspect, The Scientific Community of Students of the 21st Century. Social Sciences Electronic collection of articles on the materials of the XXXI student international scientific-practical conference, 4(30), 61-5 (2015)

15. A.A. Malyshko, Philosophical Problems of Virtual Reality: Historical and Philosophical Analysis, 164 (2008) 